\title{
Neurosteroid Replacement Therapy for Catamenial Epilepsy
}

\author{
Doodipala S. Reddy* and Michael A. Rogawski ${ }^{\dagger}$ \\ *Department of Neuroscience and Experimental Therapeutics, College of Medicine, Texas A\&M System Health Science Center, \\ College Station, Texas 77843, and Department of Neurology, School of Medicine, University of California, Davis, Sacramento,
} California 95817

\begin{abstract}
Summary: Perimenstrual catamenial epilepsy, the cyclical occurrence of seizure exacerbations near the time of menstruation, affects a high proportion of women of reproductive age with drug-refractory epilepsy. Enhanced seizure susceptibility in perimenstrual catamenial epilepsy is believed to be due to the withdrawal of the progesterone-derived $\mathrm{GABA}_{\mathrm{A}}$ receptor modulating neurosteroid allopregnanolone as a result of the fall in progesterone at the time of menstruation. Studies in a rat pseudopregnancy model of catamenial epilepsy indicate that after neurosteroid withdrawal there is enhanced susceptibility to chemoconvulsant seizures. There is also a transitory increase in the frequency of spontaneous seizures in epileptic rats that had experienced pilocarpine-induced status epilepticus. In the catamenial epilepsy model, there is a marked reduction in the antiseizure potency of anticonvulsant drugs, including benzodiazepines and valproate, but an increase in the anticonvulsant
\end{abstract}

potency and protective index of neurosteroids such as allopregnanolone and the neurosteroid analog ganaxolone. The enhanced seizure susceptibility and benzodiazepine-resistance subsequent to neurosteroid withdrawal may be related to reduced expression and altered kinetics of synaptic $\mathrm{GABA}_{\mathrm{A}}$ receptors and increased expression of $\mathrm{GABA}_{\mathrm{A}}$ receptor subunits (such as $\alpha 4$ ) that confer benzodiazepine insensitivity. The enhanced potency of neurosteroids may be due to a relative increase after neurosteroid withdrawal in the expression of neurosteroid-sensitive $\delta$-subunit-containing perisynaptic or extrasynaptic $\mathrm{GABA}_{\mathrm{A}}$ receptors. Positive allosteric modulatory neurosteroids and synthetic analogs such as ganaxolone may be administered to prevent catamenial seizure exacerbations, in what we call neurosteroid replacement therapy. Key Words: Catamenial epilepsy, progesterone, neurosteroid, allopregnanolone, ganaxolone, $\mathrm{GABA}_{\mathrm{A}}$ receptor.

\section{INTRODUCTION}

The term catamenial epilepsy is used to describe the cyclical occurrence of seizure exacerbations during particular phases of the menstrual cycle in women with preexisting epilepsy. ${ }^{1}$ The types of epilepsies and seizures that are susceptible to catamenial fluctuations have not been defined in detail. It seems, however, that seizures in both partial epilepsies (such as mesial temporal lobe epilepsy) and certain primary generalized epilepsies (such as juvenile myoclonic epilepsy) can exhibit catamenial exacerbations. ${ }^{2-4}$ It has been recognized since antiquity that the menstrual cycle can influence seizure susceptibility; however, because women with epilepsy

Address correspondence and reprint requests to: Doodipala Samba Reddy, R.Ph., Ph.D., Department of Neuroscience and Experimental Therapeutics, College of Medicine, Texas A\&M Health Science Center, 228 Reynolds Medical Building, College Station, TX 77843-1114, E-mail: reddy@medicine.tamhsc.edu; or Michael A. Rogawski, M.D., Ph.D., Department of Neurology, School of Medicine, University of California, Davis, 4860 Y Street, Suite 3700, Sacramento, CA 958172307. E-mail: rogawski@ucdavis.edu. that is severe enough to exhibit cyclical changes in seizure frequency are invariably treated with antiepileptic medications, catamenial epilepsy is now a specific form of intractable (i.e., pharmacoresistant) epilepsy. With drug treatment, some of these women experience a resolution of seizures except at certain times during the menstrual cycle; others do not respond to medications. In either case, the subjects have intractable seizures. The former situation is an example of state-dependent pharmacoresistance and may provide insight into mechanisms of drug intractability.

Catamenial seizure exacerbations are reported to affect as few as $10 \%$ or as many as $70 \%$ of women with epilepsy who are of reproductive age. ${ }^{5-8}$ The large variation in prevalence is due mainly to differences in definition. Herzog et al. ${ }^{2}$ have proposed a research definition that requires a twofold increase in average daily seizure frequency during a phase of exacerbation relative to the other phases. By this criterion, as many as one-third of women with intractable partial epilepsy meet the conditions for catamenial epilepsy. ${ }^{7}$ Herzog et al. $^{2}$ defined three forms of catamenial epilepsy: perimenstrual (C1: 
days -3 to 3 ) and periovulatory (C2: days 10 to -13$)$ in normal cycles, and luteal (C3: days 10 to 3 ) in inadequate luteal phase cycles, where day 1 is the first day of menstrual flow and ovulation is presumed to occur 14 days before the subsequent onset of menses (day -14). The most common form is perimenstrual.

Here, we describe treatment approaches for catamenial epilepsy and provide a rationale for an investigational approach for the perimenstrual form involving exogenous administration of neurosteroids or neurosteroid analogs, referred to as neurosteroid replacement therapy.

\section{NONHORMONAL TREATMENTS FOR CATAMENIAL EPILEPSY}

There are no validated therapeutic approaches to treatment of catamenial seizure exacerbations. A few anecdotal reports suggest that the carbonic anhydrase inhibitor acetazolamide may be effective. This was supported by a recent retrospective report in 20 women with temporal lobe $(n=10)$, extratemporal $(n=8)$, generalized $(n=1)$, and unclassified $(n=1)$ epilepsy, in which $30 \%$ to $40 \%$ of the patients reported improvement in the frequency and severity of perimenstrual seizure exacerbations while taking acetazolamide. ${ }^{9}$ Acetazolamide has a broad spectrum of efficacy, but its mechanism of action is not well understood. It is clear, however, that tolerance develops, which results in diminishing efficacy over time. ${ }^{10}$ This means that the drug can only be administered on an intermittent basis, which is appropriate for catamenial epilepsy but not for ordinary seizure prophylaxis. This may explain why it has been adopted for use in the treatment of catamenial seizures. Still, there may be a rational basis for its use in catamenial epilepsy.

It is generally believed that the anticonvulsant effects of carbonic anhydrase inhibitors are produced by an accumulation of $\mathrm{CO}_{2}$ in the brain, and it has been speculated that this somehow leads to reduced neuronal excitability. ${ }^{11}$ Acetazolamide, however, would also reduce intracellular bicarbonate. Outflux of bicarbonate through $\mathrm{GABA}_{\mathrm{A}}$ receptors has a depolarizing action that balances the hyperpolarization caused by influx of chloride. ${ }^{12} \mathrm{Al}$ though depolarizing GABA responses are characteristic of the immature brain, they also may occur pathologically in epileptic adult brain. ${ }^{13}$ Reduction of intracellular bicarbonate has been shown to reduce depolarizing GABA responses. ${ }^{14}$ In addition, it can be expected that there would be enhancement of synaptic and tonic $\mathrm{GABA}_{\mathrm{A}}$ receptor inhibition, mediated by perisynaptic and extrasynaptic $\mathrm{GABA}_{\mathrm{A}}$ receptors. (The role of these receptors as a target for neurosteroids is discussed later in this review.) Overall, carbonic anhydrase inhibition is expected to beneficially influence GABA inhibition and is therefore consistent with the hypothesis that altered GABA inhibition accounts for perimenstrual catamenial epilepsy, supporting the strategy of enhancing GABA inhibition as a prophylactic approach.

Synaptic $\mathrm{GABA}_{\mathrm{A}}$ receptor-mediated inhibition can also be enhanced with benzodiazepines, which are powerful broad-spectrum anticonvulsants. As is the case for acetazolamide, tolerance develops to the anticonvulsant activity of benzodiazepines, so they are of limited utility in seizure prophylaxis. Theoretically, however, they could be used on an intermittent basis for the treatment of catamenial seizures. In fact, the 1,5-benzodiazepine clobazam administered intermittently has been used to treat catamenial seizure exacerbations over long periods of time with good results. ${ }^{15}$

\section{HORMONAL BASIS OF PERIMENSTRUAL CATAMENIAL EPILEPSY}

Catamenial seizure exacerbations have been attributed to a variety of mechanisms, including fluctuations in antiepileptic drug levels and changes in water and electrolyte balance. The best accepted hypothesis posits that enhanced seizure susceptibility is related to physiological cyclic changes in ovarian hormone secretion. ${ }^{16-20}$ Whether there are abnormalities in hormonal dynamics that predispose to catamenial epilepsy is not known. The periovulatory form of catamenial epilepsy is believed to be related to the midcycle increase in estrogen secretion that occurs at the time of ovulation and that is relatively unopposed by progesterone until the early luteal phase. There is some evidence that estrogen has proconvulsant activity, although under some circumstances it may also be anticonvulsant. ${ }^{20-22}$ The molecular basis for these actions have not yet been defined.

There is more substantial evidence that the perimenstrual form is due to the withdrawal of progesterone that occurs at the time of menstruation. (An increase in the ratio of estrogen to progesterone levels during the perimenstrual period might also contribute in part to the development of perimenstrual seizure exacerbations.) The reproductive functions of progesterone are mediated via its interaction with intracellular progesterone receptors, expressed in A and B forms encoded by the same gene. The progesterone receptors are members of the nuclear receptor superfamily of transcription factors. In addition to being expressed in reproductive tissues, where they control key female reproductive events such as ovulation, maintenance of pregnancy and breast development, progesterone receptors are also expressed widely in the central nervous systems, including areas relevant to epilepsy such as the hippocampus, amygdala, and neocortex. ${ }^{23}$ We have demonstrated, however, that the anticonvulsant effects of progesterone are not reduced in mice in which the progesterone receptor gene has been deleted by gene targeting. ${ }^{24}$ This conclusively demonstrates that the seizure protection conferred by 
progesterone is not due to its interaction with progesterone receptors.

Progesterone has long been known to have anticonvulsant properties, ${ }^{16,24-27}$ and this results from its conversion to the neurosteroid allopregnanolone. ${ }^{28}$ Allopregnanolone is synthesized from progesterone by two sequential A-ring reductions catalyzed by $5 \alpha$-reductase and $3 \alpha$-hydroxysteroid oxidoreductase isoenzymes. During the menstrual cycle, circulating progesterone levels are low in the follicular phase but rise in the midluteal phase for approximately 10 to 11 days, before declining in the late luteal phase. Circulating allopregnanolone levels parallel those of its parent progesterone. ${ }^{29} \mathrm{Al}-$ though the dynamics of brain allopregnanolone during the menstrual cycle have not been studied, it is likely that local synthesis of $\mathrm{GABA}_{\mathrm{A}}$ receptor modulating neurosteroids including allopregnanolone occurs in regions relevant to epilepsy such as the cortex, hippocampus, and amygdala. ${ }^{30-32}$ Within these brain regions, neurosteroid synthetic enzymes are localized to glutamatergic principal neurons and not GABAergic inhibitory neurons; thus, neurosteroids may be synthesized within the same neurons that express their $\mathrm{GABA}_{\mathrm{A}}$ receptor targets.

The $\mathrm{GABA}_{\mathrm{A}}$ receptor modulating neurosteroid allotetrahydrodeoxycorticosterone (THDOC), which is derived from the adrenal steroid deoxycorticosterone, also fluctuates during the menstrual cycle, with higher levels in the luteal phase. ${ }^{29}$ Overall, the serum levels of THDOC are lower than those of allopregnanolone, ${ }^{33}$ so that it is likely to be less relevant to catamenial epilepsy, although it could contribute. One recent study suggested that women with catamenial epilepsy may have reduced levels of THDOC throughout the menstrual cycle; ${ }^{29}$ the significance of this finding is uncertain, but the reduced THDOC levels may be responsible for an overall enhancement of seizure susceptibility.

Allopregnanolone is a potent, broad-spectrum anticonvulsant agent that protects against seizures in diverse animal models, including various chemoconvulsant models and the $6-\mathrm{Hz}$ electroshock model, and in kindled animals. ${ }^{16,34}$ Note, however, that both progesterone and allopregnanolone exacerbate seizures in animal models of absence epilepsy. ${ }^{35,36}$ The proconvulsant effects of progesterone on absence seizures requires conversion to neurosteroids, as is the case for the anticonvulsant actions of progesterone. ${ }^{37}$ The anticonvulsant activity of allopregnanolone (and presumably also the proconvulsant activity in absence seizure models) is due to its action on $\mathrm{GABA}_{\mathrm{A}}$ receptors. ${ }^{38}$

Allopregnanolone and related neurosteroids act as positive allosteric modulators of all $\mathrm{GABA}_{\mathrm{A}}$ receptor isoforms. ${ }^{39}$ They are highly lipophilic molecules that easily cross the blood-brain barrier and, within the brain, readily diffuse into cellular membranes. Indeed, they appear to act on $\mathrm{GABA}_{\mathrm{A}}$ receptors by entry into the plasma membrane, where they access specific sites on the receptors by lateral diffusion or from the cell interior. ${ }^{40}$

$\mathrm{GABA}_{\mathrm{A}}$ receptors, the main mediators of inhibition in the central nervous system, are pentameric protein complexes surrounding a central chloride-selective ion channel. ${ }^{41}$ The major isoforms consist of two $\alpha$, two $\beta$-subunits and one $\gamma 2$-subunit, which are localized to synapses (and also can be expressed extrasynaptically). In some channels, $\delta$ substitutes for $\gamma 2$; these less abundant channels are not targeted to synapses and are believed to be principally perisynaptic (i.e., localized around the edges of synapses) and extrasynaptic. ${ }^{42}$

The modulating effects of neurosteroids occur by binding to discrete sites on the $\mathrm{GABA}_{\mathrm{A}}$ receptor that are located within the transmembrane domains of the $\alpha$ - and $\beta$-subunits that compose the receptor. ${ }^{43}$ Through homology modeling and the use of chimeras formed between $\alpha$-subunits and the neurosteroid-insensitive Rdl (Drosophila resistance to dieldrin) subunit, it has been determined that a highly conserved glutamine at position 241 in the M1 domain of the $\alpha$-subunit plays a key role in neurosteroid modulation. ${ }^{44}$ Exposure to $\mathrm{GABA}_{\mathrm{A}}$ receptor modulating neurosteroids enhances the open probability of the $\mathrm{GABA}_{\mathrm{A}}$ receptor chloride channel, so that the mean open time is increased and the mean closed time is decreased. ${ }^{40}$ This increases the chloride current through the channel, ultimately resulting in a reduction of cellular excitability.

Neurosteroids, such as allopregnanolone and THDOC, can modulate most $\mathrm{GABA}_{\mathrm{A}}$ receptor isoforms. This distinguishes neurosteroids from benzodiazepines, which act only on $\mathrm{GABA}_{\mathrm{A}}$ receptors that (i) contain $\gamma 2$-subunits and (ii) do not contain $\alpha 4$ - or $\alpha 6$-subunits. However, $\mathrm{GABA}_{\mathrm{A}}$ receptors that contain the $\delta$-subunit are more sensitive to neurosteroid-induced potentiation of GABA responses. ${ }^{45,46}$ The $\delta$-subunit does not contribute to the neurosteroid binding site, but appears to confer enhanced transduction of neurosteroid action after the neurosteroid has bound to the receptor. $\mathrm{GABA}_{\mathrm{A}}$ receptors containing the $\delta$-subunit have a low degree of desensitization and they are located perisynaptically or extrasynaptically. ${ }^{42}$ These properties cause them to be prime candidates for mediating tonic $\mathrm{GABA}_{\mathrm{A}}$ receptor current, which is activated by ambient concentrations of GABA in the extracellular space.

Tonic $\mathrm{GABA}_{\mathrm{A}}$ receptor current causes a steady inhibition of neurons and reduces their excitability. Glykys and Mody ${ }^{42}$ noted that GABA is a relatively low-efficacy agonist of $\delta$-containing $\mathrm{GABA}_{\mathrm{A}}$ receptors, even though it binds with high affinity. Neurosteroids therefore have an opportunity to markedly enhance the current generated by $\delta$-containing $\mathrm{GABA}_{\mathrm{A}}$ receptors even in the presence of saturating GABA concentrations. During seizure activity, there is expected to be substantial release of GABA from active GABAergic interneurons that can 
interact with perisynaptic and extrasynaptic $\delta$-subunitcontaining $\mathrm{GABA}_{\mathrm{A}}$ receptors. The powerful anticonvulsant activity of $\mathrm{GABA}_{\mathrm{A}}$ receptor-modulating neurosteroids is likely to be due to their action on both synaptic and perisynaptic or extrasynaptic $\mathrm{GABA}_{\mathrm{A}}$ receptors. The effect on the latter type of $\mathrm{GABA}_{\mathrm{A}}$ receptor may be more significant, given that $\delta$-subunit containing receptors are more sensitive to neurosteroids.

$\mathrm{GABA}_{\mathrm{A}}$ receptor subunit expression and the receptors composed of these subunits are not static in the cell, but rather undergo alterations that compensate for changes in the endogenous hormonal (neurosteroid) milieu and for exogenously administered pharmacological agents that modulate $\mathrm{GABA}_{\mathrm{A}}$ receptors, such as benzodiazepines or ethanol. ${ }^{47}$ The precise changes in brain $\mathrm{GABA}_{\mathrm{A}}$ receptor subunit expression occurring during the human menstrual cycle or in rat models of catamenial epilepsy have not been determined. Nonetheless, prolonged exposure to allopregnanolone in rats causes increased expression of the $\alpha 4 \mathrm{GABA}_{\mathrm{A}}$ receptor subunit in hippocampus, resulting in decreased benzodiazepine sensitivity of $\mathrm{GABA}_{\mathrm{A}}$ receptor currents. ${ }^{48}$ Although $\alpha 4$ can coassemble with $\gamma 2$ to form synaptic GABA $_{\mathrm{A}}$ receptors, it preferentially coassembles with $\delta$ to form perisynaptic and extrasynaptic $\mathrm{GABA}_{\mathrm{A}}$ receptors. ${ }^{49}$ Treatment of rats with allopregnanolone results in transient increased expression of the $\delta$-subunit in hippocampus and increased benzodiazepine-insensitive tonic current. ${ }^{50,51}$ Progesterone also increases $\delta$-subunit expression, likely as a result of conversion to allopregnanolone. ${ }^{50}$

Estrogen enhances the effect of progesterone. ${ }^{50}$ The basis of this effect of estrogen is not understood, but the phenomenon suggests that in physiological situations (such as in the pseudopregnancy model described below or during the human luteal phase, where there are high circulating estrogen levels) estrogen enhances the plasticity of $\mathrm{GABA}_{\mathrm{A}}$ receptors. The relevance of the increased $\delta$-subunit expression for catamenial epilepsy is unclear, given that $\delta$-subunit increases may be transitory and followed by reduced expression with chronic exposures, as in pregnancy ${ }^{52}$ or in the prolonged luteal phase of the human menstrual cycle.

An important consequence of the incorporation of the normally low abundance $\alpha 4$-subunit into synaptic $\mathrm{GABA}_{\mathrm{A}}$ receptors is that synaptic currents generated by these receptors have accelerated decay kinetics, so that there is less total charge transfer, which likely results in reduced inhibition. ${ }^{53} \mathrm{GABA}_{\mathrm{A}}$ receptor modulating neurosteroids cause a prolongation of the decay of GABA-mediated synaptic currents. ${ }^{54}$ Therefore, in the presence of high levels of allopregnanolone during the luteal phase, the acceleration due to $\alpha 4$ substitution is balanced. However, when neurosteroids are withdrawn at the time of menstruation, synaptic inhibition is dimin- ished from normal, resulting in enhanced excitability, which, among other effects, predisposes to seizures.

Enhanced expression of $\alpha 4$ is associated with a compensatory reduction in $\alpha 1$ expression. ${ }^{50}$ In vitro studies have also indicated that withdrawal of neurosteroids is associated with downregulation of $\alpha 1$ - and $\gamma 2$-subunit expression. ${ }^{55}$ Because the $\gamma 2$-subunit is required for synaptic clustering and targeting of $\mathrm{GABA}_{\mathrm{A}}$ receptors in dendrites, enhanced excitability may also result from a net reduction of synaptic $\mathrm{GABA}_{\mathrm{A}}$ receptors, although some studies have not detected the functional correlate of such receptor changes, which is reduced synaptic current. ${ }^{47}$ Periods of exposure to neurosteroids longer than 72 hours are associated with a return in $\alpha 4$ expression to control levels. ${ }^{47}$ The rise in $\alpha 4$ expression is therefore transitory. After prolonged periods of neurosteroid exposure, however, neurosteroid withdrawal results in a dramatic rebound rise in $\alpha 4$ expression (measured 24 hours after withdrawal). ${ }^{47,55}$ It is the withdrawal of neurosteroids around the time of menstruation, rather than the prolonged exposure to neurosteroids during the menstrual cycle luteal phase, that is likely to be most relevant to the enhanced excitability and greater seizure susceptibility in perimenstrual catamenial epilepsy.

As already mentioned, chronic exposure to neurosteroids is also accompanied by downregulation of $\delta$-subunit expression and perisynaptic and extrasynaptic $\mathrm{GABA}_{\mathrm{A}}$ receptors. ${ }^{52}$ This change is believed to be a compensatory mechanism, which would avoid excessive sedation caused by high neurosteroid levels acting on sensitive $\delta$-subunit-containing $\mathrm{GABA}_{\mathrm{A}}$ receptors. At the time of neurosteroid withdrawal, $\delta$-subunit expression rapidly recovers. If recovery is not sufficiently fast, however, there could be an enhancement of excitability due to a reduction in tonic inhibition mediated by perisynaptic and extrasynaptic $\mathrm{GABA}_{\mathrm{A}}$ receptors in the relative absence of neurosteroids.

Overall, the basis for the enhanced seizure susceptibility in perimenstrual catamenial epilepsy is multifaceted and may include (i) withdrawal of the anticonvulsant effects of neurosteroids mediated through their action on $\mathrm{GABA}_{\mathrm{A}}$ receptors, (ii) increased expression of $\mathrm{GABA}_{\mathrm{A}}$ receptor $\alpha 4$-subunits especially after neurosteroid withdrawal, resulting in reduced GABA-mediated synaptic inhibition due to an acceleration in the decay of GABA-mediated synaptic currents, (iii) overall reduction in $\mathrm{GABA}_{\mathrm{A}}$ receptor-mediated synaptic inhibition due to reduced expression of $\mathrm{GABA}_{\mathrm{A}}$ receptor subunits (such as $\alpha 1$ and $\gamma 2$ ) that compose synaptic $\mathrm{GABA}_{\mathrm{A}}$ receptors, and (iv) reduced expression of extrasynaptic ( $\delta$-subunitcontaining) $\mathrm{GABA}_{\mathrm{A}}$ receptors and insufficiently rapid recovery at the time of neurosteroid withdrawal. All of these factors are related to the high levels of circulating neurosteroids during the luteal phase and the natural 

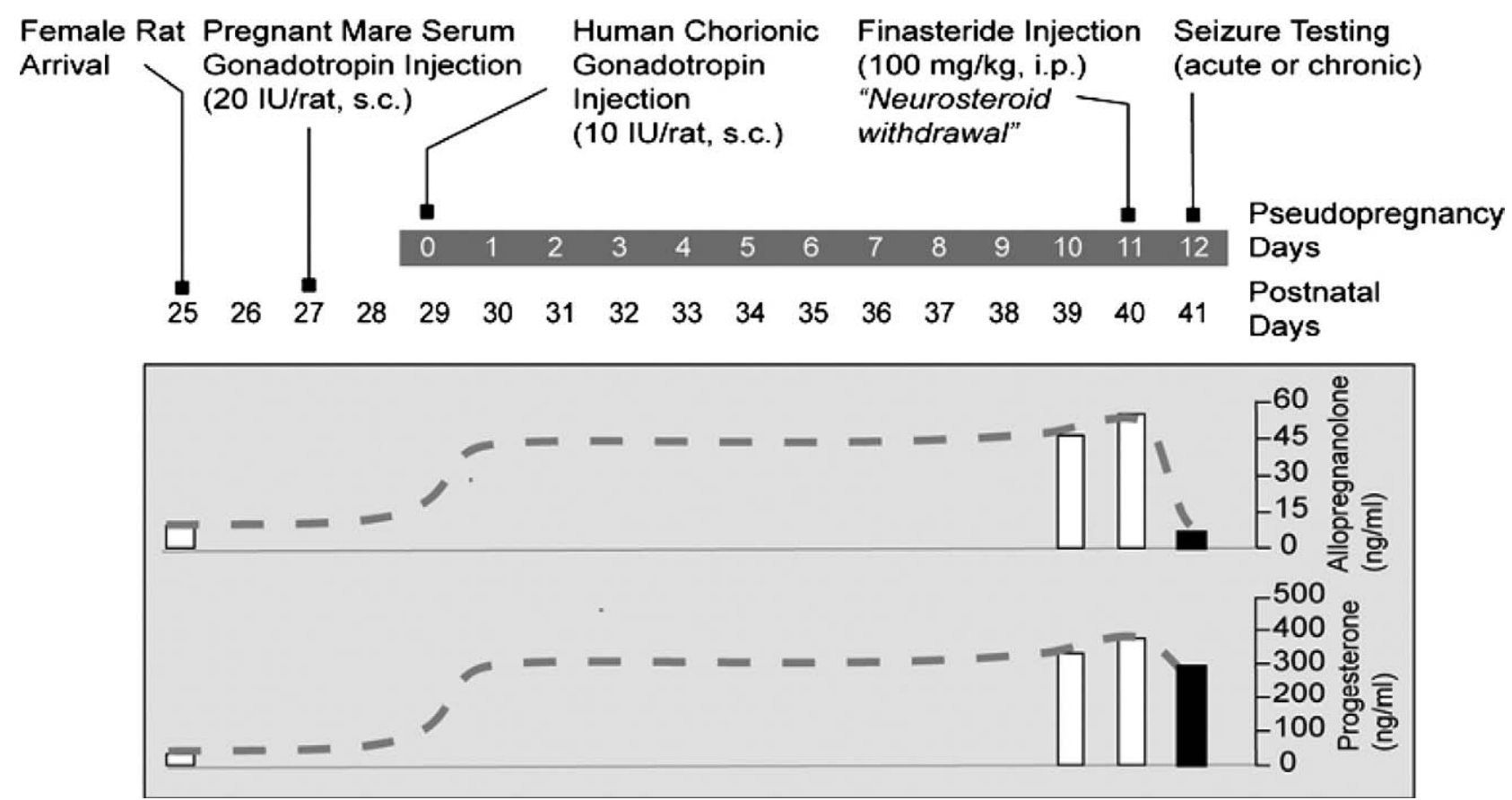

FIG. 1. Rat neurosteroid withdrawal model of catamenial seizure exacerbations. Rats are treated sequentially with pregnant mare serum gonadotropin and human chorionic gonadotropin according to a protocol, described by Kim and Greenwald, ${ }^{59}$ that hyperstimulates the ovary to induce massive ovarian luteinization, resulting in prolonged elevated serum progesterone levels (described as a state of pseudopregnancy). On day 11 of pseudopregnancy, animals are treated with the $5 \alpha$-reductase inhibitor finasteride, which blocks the conversion of progesterone to the neurosteroid allopregnanolone, resulting in neurosteroid withdrawal. Acute seizure testing is performed on the day after finasteride administration. For studies of effects of neurosteroid withdrawal on spontaneous seizures (see FIG. $2 \mathrm{~B}$ ), the gonadotropin treatment was initiated 5 months after pilocarpine-induced status epilepticus. Progesterone and allopregnanolone plasma levels are from Reddy et al. ${ }^{56}$; dashed lines schematically illustrate the time course of the fluctuations in hormone levels and do not represent actual measurements (except for the data points indicated with bars). The drop in allopregnanolone levels after finasteride treatment is significant, but the change in progesterone is not significant.

reduction or withdrawal of progesterone that occurs around the time of menstruation.

\section{RAT MODEL OF CATAMENIAL EPILEPSY}

To better understand the biological basis of catamenial seizure exacerbations and to evaluate potential therapies, we developed a rodent model (FIG. 1) that is designed to simulate the hormonal changes that are believed to be relevant to perimenstrual catamenial epilepsy. ${ }^{56}$ Rodents, which are the main mammalian species used for experimental epilepsy research, have a 4 to 5 day estrous cycle. Studies of fluctuations in seizure susceptibility during the estrous cycle have not provided results that are relevant to the 28-day human menstrual cycle. ${ }^{57} \mathrm{We}$ therefore attempted to simulate human hormonal menstrual changes in the rat.

The basic requirement is prolonged high levels of progesterone followed by withdrawal, to stimulate the fall in ovarian secretion that occurs at the time of menstruation. Abrupt discontinuation of progesterone after chronic treatment for 3 weeks leads to proconvulsant effects. ${ }^{58}$ This can be considered a rudimentary model of catamenial epilepsy. A more physiological means of inducing elevated progesterone (and other hormonal changes of the human luteal phase, such as increased estrogen) is a hormonal treatment regimen with pregnant mare's serum gonadotropin (PMSG) and human chorionic gonadotropin (hCG), as is commonly used to induce superovulation. ${ }^{59}$ This state has been referred to as pseudopregnancy, ${ }^{60}$ because it is an anestrous condition (cessation of estrous cyclicity) associated with changes in the reproductive organs and mammary glands that simulate those occurring in pregnancy.

During pseudopregnancy in the rat, which persists for 12 to 13 days, progesterone and estrogen levels are similar to those in the luteal phase of the human menstrual cycle. (Pseudopregnancy is ordinarily induced in female rats by vaginocervical stimulation, but gonadotropin treatment produces more reliable and robust sex steroid elevations.) Abrupt withdrawal from progesterone-derived neurosteroids, as is believed to occur around the time of menstruation in humans, can be induced either by ovariectomy or by injection of a $5 \alpha$-reductase inhibitor that blocks neurosteroid synthesis. ${ }^{28}$ Such neurosteroid withdrawal is associated with a marked enhancement in anxiety-like behaviors and seizure susceptibility. ${ }^{56,60} \mathrm{We}$ have proposed that the period of heightened seizure susceptibility represents a model of human perimenstrual catamenial seizure exacerbations. ${ }^{56}$ 

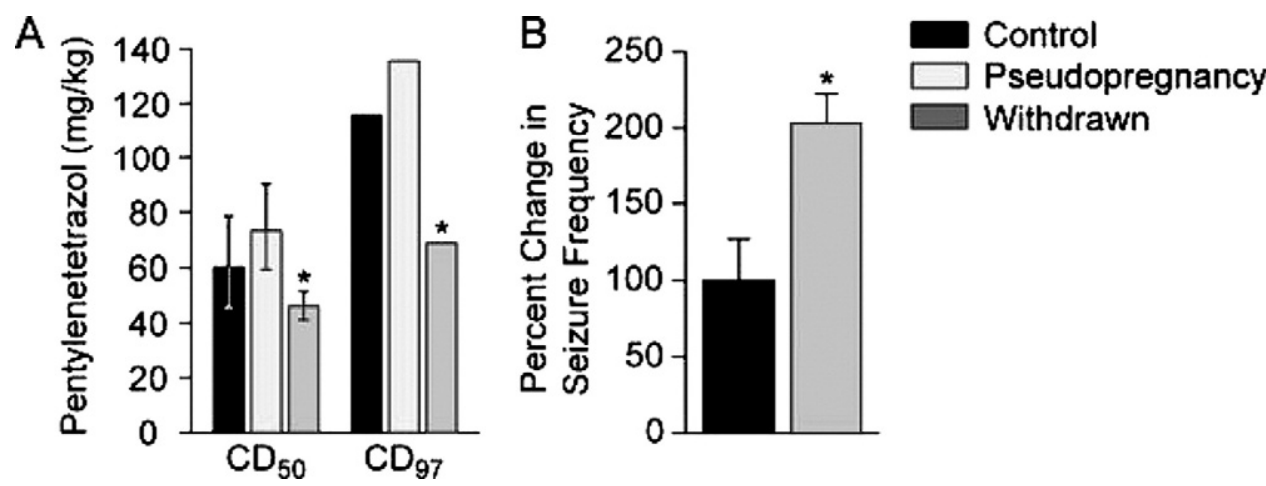

FIG. 2. Enhanced seizure susceptibility after neurosteroid withdrawal in an acute rat seizure model (pentylenetetrazol-induced clonic convulsions) and in a chronic epilepsy model (spontaneous recurrent seizures after pilocarpine status epilepticus). A: Convulsant doses of pentylenetetrazol for $50 \%\left(C_{50}\right)$ and $97 \%\left(C D_{97}\right)$ of rats in (i) control diestrous, (ii) nonwithdrawn (vehicle-treated) pseudopregnant, and (iii) finasteride-treated (neurosteroid-withdrawn) pseudopregnant animals. The $C_{50}$ and $C D_{97}$ values in withdrawn animals is significantly reduced, compared with the values from control diestrous animals and from nonwithdrawn pseudopregnant animals $(p<$ 0.05), indicating greater seizure susceptibility (data adapted from Reddy et al. ${ }^{56}$ ). B: Increased seizure frequency after neurosteroid withdrawal (catamenial seizure model) in epileptic animals 5 months after pilocarpine treatment. At the end of the 11 days of pseudopregnancy, rats on average exhibited approximately 2 seizures per day ( $=100 \%$; black bar). On the day after neurosteroid withdrawal (day 12), seizure frequency increased twofold relative to the prewithdrawal value (4 seizures per day; $p<0.05)$. The seizure frequency partially recovered to 2.8 seizures per day 2 days after withdrawal (day 13), which was within the baseline seizure frequency (2.6-3.0 seizures per day on days 1-2 of pseudopregnancy) (not shown) (data from unpublished study).

The pseudopregnancy neurosteroid withdrawal model has until recently been applied only with normal healthy rats induced to have seizures with pentylenetetrazol. However, Reddy and Zeng ${ }^{61}$ have begun to apply the model in female rats that had experienced an episode of pilocarpine status epilepticus and that exhibit spontaneous recurrent seizures. These epileptic animals exhibit a transient increase in the frequency of spontaneous seizures after neurosteroid withdrawal (FIG. 2B). The use of epileptic animals with spontaneous recurrent seizures has greater face validity for catamenial epilepsy than does the pentylenetetrazol threshold method (FIG. 2A). Although this new approach could possibly be more relevant to human epilepsy, it is substantially more labor intensive and is not well suited for extensive pharmacological studies.

\section{PHARMACOLOGY OF THE CATAMENIAL EPILEPSY MODEL}

The neurosteroid withdrawal model of catamenial epilepsy has been used to investigate therapies for perimenstrual catamenial epilepsy. ${ }^{62,63}$ A key result is the observation that conventional antiepileptic drugs have reduced potency in protecting against seizures during the period of enhanced seizure susceptibility after neurosteroid withdrawal. These studies necessarily involved drugs effective against pentylenetetrazol seizures, including benzodiazepines and valproate, which were the type of seizures used with the model. The dose-response curves for seizure protection by these agents was shifted to the right in the period of enhanced seizure susceptibility after neurosteroid withdrawal, indicating reduced potency (FIG. 3B).
Extrapolating these results to women with perimenstrual catamenial epilepsy suggests that seizure exacerbations may, at least in part, result from a state-dependent reduction in drug sensitivity. The model therefore represents a conditional form of antiepileptic drug pharmacoresistance of the antiepileptic drug target type. ${ }^{64}$ The increased relative expression of benzodiazepine-insensitive $\mathrm{GABA}_{\mathrm{A}}$ receptors at the time of neurosteroid withdrawal likely accounts for the reduced activity of benzodiazepines. The basis for the reduced activity of other anticonvulsant drugs is harder to define. In particular, there was a profound reduction in valproate potency, but it is difficult to speculate on the cause because the molecular mechanism of action of valproate is not well understood.

In contrast to the results with conventional anticonvulsant drugs, we unexpectedly found that neurosteroids, including allopregnanolone and THDOC and their $5 \beta$ isomers, as well as the barbiturate phenobarbital (all of which are positive allosteric modulators of $\mathrm{GABA}_{\mathrm{A}}$ receptors) had enhanced activity in the perimenstrual catamenial epilepsy model. ${ }^{63}$ Extensive studies were conducted with the neurosteroid analog ganaxolone (FIG. $3)^{62}$ Ganaxolone is the synthetic $3 \beta$-methyl derivative of allopregnanolone ${ }^{65-68}$ (FIG. 3A). The $3 \beta$-methyl substituent minimizes back conversion by bidirectional $3 \alpha-$ hydroxysteroid oxidoreductase isoenzymes to the hormonally active 3-keto form. Hence, ganaxolone lacks hormonal activity, unlike the endogenous neurosteroid allopregnanolone, which may have hormonally active metabolites.

Ganaxolone has pharmacological activity, including $\mathrm{GABA}_{\mathrm{A}}$ receptor modulating activity and anticonvulsant 
A<smiles>CC(=O)C1CCC2C3CC[C@H]4CC(C)(O)CCC4(C)[C@H]3CC[C@]12C</smiles><smiles>CC12CC[C@H](O)C[C@H]1CCC1C2CC[C@]2(C)C(C(=O)CO)CCC12</smiles>

Progesterone

Allopregnanolone

Ganaxolone

THDOC
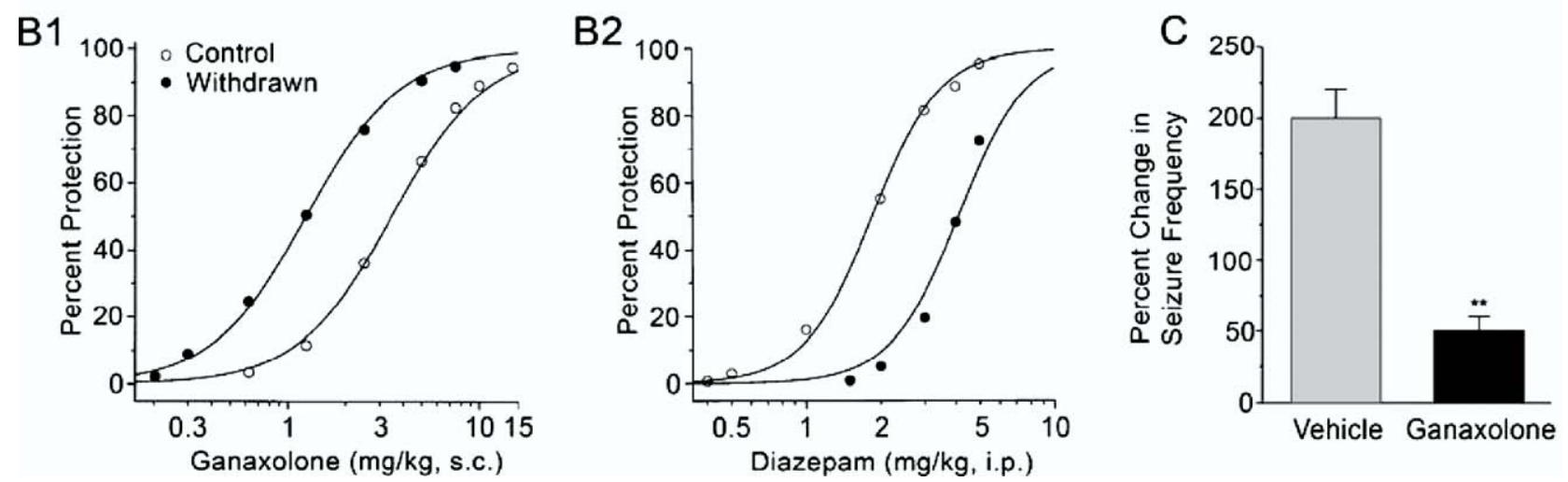

FIG. 3. A: Chemical structure of progesterone, the endogenous neurosteroids allopregnanolone and THDOC, and the synthetic allopregnanolone analog ganaxolone. Allopregnanolone is derived from progesterone by reduction at the 5- and 3-positions of the steroid A-ring. Ganaxolone differs from allopregnanolone by a $3 \beta$-methyl group (shown in blue). B1: Anticonvulsant potency of ganaxolone is enhanced during the period of increased seizure susceptibility in the pseudopregnancy withdrawal model of catamenial epilepsy. Dose-response curves for ganaxolone protection against pentylenetetrazol-induced seizures in naïve female rats (control) and finasteride-treated pseudopregnant rats (withdrawn). The shift to the left indicates increased potency. B2: Anticonvulsant potency of diazepam is reduced during the period of increased seizure susceptibility in the model of catamenial epilepsy. Dose-response curve for diazepam protection against pentylenetetrazol-induced seizures is shifted to the right in withdrawn animals, indicating reduced potency. In the withdrawn animals (B1 and B2), seizure testing with pentylenetetrazol was performed on day 12 of pseudopregnancy (24 $\mathrm{h}$ after finasteride administration). (Adapted from Reddy and Rogawski. ${ }^{62}$ ) C: Antiseizure effects of ganaxolone (7 mg/kg, s.c.) against spontaneous seizures in epileptic rats after neurosteroid withdrawal (see FIG. 1). Data values represent percent change in relation to average daily seizure frequency in control group. Ganaxolone treatment significantly $(p<0.01)$ reduced the frequency of spontaneous seizures compared with vehicle controls.

properties in animal models that is similar to that of the parent allopregnanolone. As with naturally occurring neurosteroids, the anticonvulsant potency of ganaxolone was enhanced after neurosteroid withdrawal. ${ }^{62}$ Neurosteroid-withdrawn rats receiving a single dose of ganaxolone $(7 \mathrm{mg} / \mathrm{kg}$, s.c.) exhibited markedly increased protective activity in the pentylenetetrazol threshold test, compared with control animals. ${ }^{69}$ Ganaxolone plasma and brain levels were not increased in neurosteroid-withdrawn animals, and therefore the enhanced potency of ganaxolone was not due to pharmacokinetic factors. In fact, brain ganaxolone levels were modestly reduced in withdrawn animals; the pharmacokinetic basis for this effect is uncertain. Based on the relationship between brain ganaxolone concentrations and the corresponding pentylenetetrazol thresholds, there was an approximately $70 \%$ elevation in threshold for any active brain ganaxolone concentration in the withdrawn animals, compared with controls. The enhanced activity of ganaxolone was independent of brain concentration and must relate to alterations in pharmacodynamic activity. Although the molecular basis is still uncertain, it presumably results from alterations in $\mathrm{GABA}_{\mathrm{A}}$ receptor sensitivity.

Specifically, it may relate to the relative increase in neurosteroid-sensitive $\delta$-subunit containing $\mathrm{GABA}_{\mathrm{A}}$ receptors discussed previously. Notably, the motor toxicity of ganaxolone was not increased in neurosteroid-withdrawn animals, ${ }^{62}$ indicating that the alterations in $\mathrm{GABA}_{\mathrm{A}}$ receptors that account for the potentiated anticonvulsant activity are not relevant to the general sedative activity of the steroid, which is the main side effect of neurosteroids and other $\mathrm{GABA}_{\mathrm{A}}$ receptor-positive modulators. Because of the selective increase in anticonvulsant potency, the therapeutic window of ganaxolone (ratio of $\mathrm{TD}_{50}$ for motor impairment and $\mathrm{ED}_{50}$ for seizure protection in pentylenetetrazol test) is increased from 1.6 in control rats to 6.4 in pseudopregnant neurosteroidwithdrawn animals. ${ }^{62}$

In recent studies, the anticonvulsant activity of ganaxolone was examined in rats with spontaneous seizures that had experienced pilocarpine status epilepticus. Ganaxolone administered after neurosteroid withdrawal sig- 
nificantly reduced the occurrence of spontaneous seizures in these animals (FIG. 3C), further confirming its potential utility in the treatment of perimenstrual catamenial epilepsy.

\section{NEUROSTEROID REPLACEMENT THERAPY}

Our pharmacological results with the pseudopregnancy animal model of catamenial epilepsy suggest that neurosteroid replacement may be a useful approach to prevent catamenial seizure exacerbations. A neurosteroid or a neurosteroid-like compound such as ganaxolone could be administered in a pulse prior to menstruation and then withdrawn, or it could be continuously administered throughout the month. Although intermittent administration at the time of increased seizure vulnerability is rational, continuous administration would avoid withdrawal of the therapeutic agent, which itself could predispose to seizures. This factor, as well as the practical difficulty many women experience in predicting the time of their menstrual periods, suggests that continuous administration is preferred.

The neuroactive steroid would be administered at low doses to avoid sedative side effects. Such low doses are expected to contribute little anticonvulsant activity during most of the menstrual cycle, and so patients would require treatment with conventional antiepileptic medications. During the period of enhanced seizure susceptibility at the time of menstruation, however, the increased potency of the neurosteroid would confer protection against perimenstrual seizure exacerbations. Notably, anticonvulsant tolerance does not develop to ganaxolone and other $\mathrm{GABA}_{\mathrm{A}}$ receptor modulating neurosteroids after chronic therapy in rodents, ${ }^{70,71}$ indicating that these agents, unlike benzodiazepines, may be suitable for chronic treatment. Nonetheless, dosing may need to be adjusted to account for alterations in metabolism occurring with chronic exposure.

To date, 961 human subjects (including 135 children) have been exposed to ganaxolone in safety and pharmacokinetic studies (260 subjects) and various clinical trials (701 subjects). The drug is well tolerated, but causes reversible sedation and somnolence, which is dose limiting. Ganaxolone is metabolized by CYP3A to 16-hydroxyganaxolone, which is inactive, and then to various multihydroxylated metabolites. Despite this route of metabolism, the information available to date indicates that ganaxolone will have low drug-drug interactions. It could therefore be administered easily with concomitant antiepileptic drugs.

In a preliminary uncontrolled open-label study, ganaxolone was evaluated in two women with catamenial epilepsy, who appeared to have a reduction in their catamenial seizures. ${ }^{72}$ These women received oral ganaxolone (300 mg/day, b.i.d.) starting on day 21 of the menstrual cycle and continuing through the 3rd full day after the beginning of menstruation. Prospective clinical studies are warranted to validate these preliminary observations.

\section{CONCLUSIONS}

Catamenial epilepsy is a multifaceted neuroendocrine condition. In perimenstrual catamenial epilepsy, the most common form, there is emerging evidence to suggest that neurosteroid withdrawal plays a key role in the seizure exacerbations that occur around the time of menstruation. There are currently no specific approved treatments to prevent seizure exacerbations in this condition. Anecdotal evidence suggests that progesterone may be effective, ${ }^{73,74}$ and a multicenter controlled trial is underway. However, progesterone is poorly absorbed orally and has a short half-life, so that it must be administered multiple times per day. Furthermore, the activity of progesterone is likely to be dependent upon conversion to allopregnanolone, and consequently individual variation in metabolism could cause variability in the response to therapy. An additional concern is that progesterone may be associated with undesired hormonal side effects. Neurosteroids and synthetic analogs such as ganaxolone might provide an effective approach for catamenial epilepsy therapy that is more reliable and does not expose patients to the risk of hormonal side effects. New oral formulations of ganaxolone are being developed with enhanced bioavailability and more consistent absorption. The treatment of catamenial epilepsy is a promising application for this investigational agent.

\section{Disclosure}

M.A.R. is a scientific founder of and has served as consultant to Marinus Pharmaceuticals, Inc., Branford, CT.

Acknowledgments: This work was supported by National Institutes of Health grant 7R21NS052158-03 (to D.S.R.).

\section{REFERENCES}

1. Newmark ME, Penry JK. Catamenial epilepsy: a review. Epilepsia 1980;21:281-300.

2. Herzog AG, Klein P, Ransil BJ. Three patterns of catamenial epilepsy. Epilepsia 1997;38:1082-1088.

3. Panayiotopoulos CP, Obeid T, Tahan AR. Juvenile myoclonic epilepsy: a 5-year prospective study. Epilepsia 1994;35:285-296.

4. Agathonikou A, Koutroumanidis M, Panayiotopoulos CP. Fixation-off-sensitive epilepsy with absences and absence status: video-EEG documentation. Neurology 1997;48:231-234.

5. Duncan S, Read CL, Brodie MJ. How common is catamenial epilepsy? Epilepsia 1993;34:827-831.

6. Taubøll E, Lundervold A, Gjerstad L. Temporal distribution of seizures in epilepsy. Epilepsy Res 1991;8:153-165.

7. Herzog AG, Harden CL, Liporace J, et al. Frequency of catamenial seizure exacerbation in women with localization-related epilepsy. Ann Neurol 2004;56:431-434.

8. Bazan AC, Montenegro MA, Cendes F, Min LL, Guerreiro CA. Menstrual cycle worsening of epileptic seizures in women with 
symptomatic focal epilepsy. Arq Neuropsiquiatr 2005;63(3B): 751-756.

9. Lim LL, Foldvary N, Mascha E, Lee J. Acetazolamide in women with catamenial epilepsy. Epilepsia 2001;42:746-749.

10. Browne TR, Leduc BW, Kosta-Rokosz MD, Bromfield EB, Ramsay RE, De Toledo J. Trimethadione, paraldehyde, phenacemide, bromides, sulthiame, acetazolamide, and methsuximide. In: Engel J Jr, Pedley TA, Epilepsy, a comprehensive textbook. $2^{\text {nd }}$ ed. Philadelphia: Wolters Kluwer Health/Lippincott Williams \& Wilkins, 2008:1703-1719.

11. Rogawski MA, Porter RJ. Antiepileptic drugs: pharmacological mechanisms and clinical efficacy with consideration of promising developmental stage compounds. Pharmacol Rev 1990;42:223286.

12. Staley KJ, Soldo BL, Proctor WR. Ionic mechanisms of neuronal excitation by inhibitory $\mathrm{GABA}_{\mathrm{A}}$ receptors. Science 1995;269:977981.

13. Pathak HR, Weissinger F, Terunuma M, et al. Disrupted dentate granule cell chloride regulation enhances synaptic excitability during development of temporal lobe epilepsy. J Neurosci 2007;27: 14012-14022.

14. Bonnet U, Bingmann D. $\mathrm{GABA}_{\mathrm{A}}$-responses of $\mathrm{CA} 3$ neurones: contribution of bicarbonate and of $\mathrm{Cl}^{-}$-extrusion mechanisms. Neuroreport 1995;6:700-704.

15. Feely M, Gibson J. Intermittent clobazam for catamenial epilepsy. J Neurol Neurosurg Psychiatry 1984;47:1279-1282.

16. Rogawski MA, Reddy DS. Neurosteroids: endogenous modulators of seizure susceptibility. In: Rho JM, Sankar R, Cavazos JE, Epilepsy: scientific foundations of clinical practice. New York: Marcel Dekker, 2004:319-355.

17. Reddy DS. Role of neurosteroids in catamenial epilepsy. Epilepsy Res 2004;62:99-118.

18. Reddy DS. Perimenstrual catamenial epilepsy. Women's Health 2007;3(2):195-206.

19. Bonuccelli U, Melis GB, Paoletti AM, Fioretti P, Murri L, Muratorio A. Unbalanced progesterone and estradiol secretion in catamenial epilepsy. Epilepsy Res 1989;3:100-106.

20. Scharfman HE, MacLusky NJ. The influence of gonadal hormones on neuronal excitability, seizures and epilepsy in the female. Epilepsia 2006;47:1423-1440.

21. Buterbaugh GG. Estradiol replacement facilitates the acquisition of seizures kindled from the anterior neocortex in female rats. Epilepsy Res 1989;4:207-215.

22. Velí̌́ková J. Estrogens and epilepsy: why are we so excited? Neuroscientist 2007;13:77-88.

23. Brinton RD, Thompson RF, Foy MR, et al. Progesterone receptors: form and function in brain. Front Neuroendocrinol 2008;29:313339.

24. Reddy DS, Castaneda DC, O'Malley BW, Rogawski MA. Anticonvulsant activity of progesterone and neurosteroids in progesterone receptor knockout mice. J Pharmacol Exp Ther 2004;310: 230-239.

25. Selye H. Antagonism between anesthetic steroid hormones and pentamethylenetetrazol (Metrazol). J Lab Clin Med 1942;27:10511053.

26. Frye CA, Rhodes ME, Walf A, Harney J. Progesterone reduces pentylenetetrazol-induced ictal activity of wild-type mice but not those deficient in type I $5 \alpha$-reductase. Epilepsia 2002;43 Suppl 5:14-17.

27. Lonsdale D, Burnham WM. The anticonvulsant effects of progesterone and $5 \alpha$-dihydroprogesterone on amygdala-kindled seizures in rats. Epilepsia 2003;44:1494-1499.

28. Kokate TG, Banks MK, Magee T, Yamaguchi S, Rogawski MA. Finasteride, a $5 \alpha$-reductase inhibitor, blocks the anticonvulsant activity of progesterone in mice. J Pharmacol Exp Ther 1999;288: $679-684$

29. Tuveri A, Paoletti AM, Orrù M, et al. Reduced serum level of THDOC, an anticonvulsant steroid, in women with perimenstrual catamenial epilepsy. Epilepsia 2008;49:1221-1229.

30. Ebner MJ, Corol DI, Havlíková H, Honour JW, Fry JP. Identification of neuroactive steroids and their precursors and metabolites in adult male rat brain. Endocrinology 2006;147:179-190.
31. Agís-Balboa RC, Pinna G, Zhubi A, et al. Characterization of brain neurons that express enzymes mediating neurosteroid biosynthesis. Proc Natl Acad Sci U S A 2006;103:14602-14607.

32. Mukai Y, Higashi T, Nagura Y, Shimada K. Studies on neurosteroids: XXV. Influence of a $5 \alpha$-reductase inhibitor, finasteride, on rat brain neurosteroid levels and metabolism. Biol Pharm Bull 2008;31:1646-1650.

33. Hardoy MC, Sardu C, Dell'osso L, Carta MG. The link between neurosteroids and syndromic/syndromal components of the mood spectrum disorders in women during the premenstrual phase. Clin Pract Epidemol Ment Health 2008;4:3.

34. Kaminski RM, Livingood MR, Rogawski MA. Allopregnanolone analogs that positively modulate GABA receptors protect against partial seizures induced by $6-\mathrm{Hz}$ electrical stimulation in mice. Epilepsia 2004;45:864-867.

35. van Luijtelaar G, Budziszewska B, Jaworska-Feil L, Ellis J, Coenen A, Lasoń W. The ovarian hormones and absence epilepsy: a long-term EEG study and pharmacological effects in a genetic absence epilepsy model. Epilepsy Res 2001;46:225-239.

36. Snead OC 3rd. Ganaxolone, a selective, high-affinity steroid modulator of the $\gamma$-aminobutyric acid-A receptor, exacerbates seizures in animal models of absence. Ann Neurol 1998;44:688-691.

37. van Luijtelaar G, Budziszewska B, Tetich M, Lasoń W. Finasteride inhibits the progesterone-induced spike-wave discharges in a genetic model of absence epilepsy. Pharmacol Biochem Behav 2003; 75:889-894.

38. Kokate TG, Svensson BE, Rogawski MA. Anticonvulsant activity of neurosteroids: correlation with $\gamma$-aminobutyric acid-evoked chloride current potentiation. J Pharmacol Exp Ther 1994;270: 1223-1229.

39. Lambert JJ, Belelli D, Peden DR, Vardy AW, Peters JA. Neurosteroid modulation of $\mathrm{GABA}_{\mathrm{A}}$ receptors. Prog Neurobiol 2003;71: $67-80$.

40. Akk G, Shu HJ, Wang C, et al. Neurosteroid access to the $\mathrm{GABA}_{\mathrm{A}}$ receptor. J Neurosci 2005;25:11605-11613.

41. Meldrum BS, Rogawski MA. Molecular targets for antiepileptic drug development. Neurotherapeutics 2007;4:18-61.

42. Glykys J, Mody I. Activation of $\mathrm{GABA}_{\mathrm{A}}$ receptors: views from outside the synaptic cleft. Neuron 2007;56:763-770.

43. Hosie AM, Wilkins ME, Smart TG. Neurosteroid binding sites on GABA $_{\mathrm{A}}$ receptors. Pharmacol Ther 2007;116:7-19.

44. Hosie AM, Clarke L, da Silva H, Smart TG. Conserved site for neurosteroid modulation of $\mathrm{GABA}_{\mathrm{A}}$ receptors. Neuropharmacology 2009;56:149-154.

45. Belelli D, Casula A, Ling A, Lambert JJ. The influence of subunit composition on the interaction of neurosteroids with $\mathrm{GABA}_{\mathrm{A}}$ receptors. Neuropharmacology 2002;43:651-661.

46. Wohlfarth KM, Bianchi MT, Macdonald RL. Enhanced neurosteroid potentiation of ternary $\mathrm{GABA}_{\mathrm{A}}$ receptors containing the $\delta$ subunit. J Neurosci 2002;22:1541-1549.

47. Smith SS, Shen H, Gong QH, Zhou X. Neurosteroid regulation of $\mathrm{GABA}_{\mathrm{A}}$ receptors: focus on the $\alpha 4$ and $\delta$ subunits. Pharmacol Ther 2007; 116:58-76.

48. Gulinello M, Gong QH, Li X, Smith SS. Short-term exposure to a neuroactive steroid increases $\alpha 4 \mathrm{GABA}_{\mathrm{A}}$ receptor subunit levels in association with increased anxiety in the female rat. Brain Res 2001;910:55-66.

49. Sur C, Farrar SJ, Kerby J, Whiting PJ, Atack JR, McKernan RM. Preferential coassembly of $\alpha 4$ and $\gamma$ subunits of the $\gamma$-aminobutyric acid $_{\mathrm{A}}$ receptor in rat thalamus. Mol Pharmacol 1999;56:110115 .

50. Shen H, Gong QH, Yuan M, Smith SS. Short-term steroid treatment increases $\delta \mathrm{GABA}_{\mathrm{A}}$ receptor subunit expression in rat CA1 hippocampus: pharmacological and behavioral effects. Neuropharmacology 2005;49:573-586.

51. Maguire JL, Stell BM, Rafizadeh M, Mody I. Ovarian cycle-linked changes in $\mathrm{GABA}_{\mathrm{A}}$ receptors mediating tonic inhibition alter seizure susceptibility and anxiety. Nat Neurosci 2005;8:797-804.

52. Maguire J, Mody I. GABA $\mathrm{A}$ plasticity during pregnancy: relevance to postpartum depression. Neuron 2008;59:207-213.

53. Smith SS, Gong QH. Neurosteroid administration and withdrawal alter $\mathrm{GABA}_{\mathrm{A}}$ receptor kinetics in CA1 hippocampus of female rats. J Physiol 2005;564(Pt 2):421-436. 
54. Belelli D, Lambert JJ. Neurosteroids: endogenous regulators of the $\mathrm{GABA}_{\mathrm{A}}$ receptor. Nat Rev Neurosci 2005;6:565-575.

55. Mascia MP, Biggio F, Mancuso L, et al. Changes in $\mathrm{GABA}_{\mathrm{A}}$ receptor gene expression induced by withdrawal of, but not by long-term exposure to, ganaxolone in cultured rat cerebellar granule cells. J Pharmacol Exp Ther 2002;303:1014-1020.

56. Reddy DS, Kim HY, Rogawski MA. Neurosteroid withdrawal model of perimenstrual catamenial epilepsy. Epilepsia 2001;42: $328-336$.

57. Finn DA, Gee KW. The estrus cycle, sensitivity to convulsants and the anticonvulsant effect of a neuroactive steroid. J Pharmacol Exp Ther 1994;271:164-170.

58. Smith SS, Gong QH, Hsu FC, Markowitz RS, ffrench-Mullen $\mathrm{JMH}, \mathrm{Li} \mathrm{X} . \mathrm{GABA}_{\mathrm{A}}$ receptor $\alpha 4$ subunit suppression prevents withdrawal properties of an endogenous steroid. Nature 1998;392: 926-930.

59. Kim I, Greenwald GS. Steroidogenic effects of lipoproteins and 25-hydroxycholesterol on luteal and ovarian cells: a comparison of two pseudopregnant rat models. Proc Soc Exp Biol Med 1986;181: 242-248.

60. Smith SS, Gong QH, Li X, et al. Withdrawal from $3 \alpha-\mathrm{OH}-5 \alpha$ pregnan-20-one using a pseudopregnancy model alters the kinetics of hippocampal $\mathrm{GABA}_{\mathrm{A}}$-gated current and increases the $\mathrm{GABA}_{\mathrm{A}}$ receptor $\alpha 4$ subunit in association with increased anxiety. J Neurosci 1998; 18:5275-5284.

61. Reddy DS, Zeng YC. Effect of neurosteroid withdrawal on spontaneous recurrent seizures in a rat model of catamenial epilepsy. FASEB J 2007;21:885.14 (abstract)

62. Reddy DS, Rogawski MA. Enhanced anticonvulsant activity of ganaxolone after neurosteroid withdrawal in a rat model of catamenial epilepsy. J Pharmacol Exp Ther 2000;294:909-915.

63. Reddy DS, Rogawski MA. Enhanced anticonvulsant activity of neuroactive steroids in a rat model of catamenial epilepsy. Epilepsia 2001;42:337-344.
64. Remy S, Beck H. Molecular and cellular mechanisms of pharmacoresistance in epilepsy. Brain 2006;129(Pt 1):18-35.

65. Carter RB, Wood PL, Wieland S, et al. Characterization of the anticonvulsant properties of ganaxolone (CCD 1042; $3 \alpha$-hydroxy$3 \beta$-methyl-5 $\alpha$-pregnan-20-one), a selective, high-affinity, steroid modulator of the $\gamma$-aminobutyric acid $_{\mathrm{A}}$ receptor. J Pharmacol Exp Ther 1997;280:1284-1295.

66. Reddy DS, Woodward R. Ganaxolone: a prospective overview. Drugs Future 2004;29:227-242.

67. Nohria V, Giller E. Ganaxolone. Neurotherapeutics 2007:4:102105.

68. Garofalo E, Tsai J, Shaw K, Rogawski MA, Pieribone V. Ganaxolone . In: Bialer M, Johannessen SI, Levy RH, Perucca E, Tomson T, White HS, Progress report on new antiepileptic drugs: a summary of the Ninth Eilat Conference (EILAT IX). Epilepsy Res 2009;83:1-43.

69. Reddy DS, Rogawski MA. Pharmacokinetic-pharmacodynamic comparison of ganaxolone in normal rats and in a rat model of catamenial epilepsy. Epilepsia 2008:49 Suppl 7:371 (Abstract 3.082).

70. Kokate TG, Yamaguchi S, Pannell LK, et al. Lack of anticonvulsant tolerance to the neuroactive steroid pregnanolone in mice. J Pharmacol Exp Ther 1998;287:553-558.

71. Reddy DS, Rogawski MA. Chronic treatment with the neuroactive steroid ganaxolone in the rat induces anticonvulsant tolerance to diazepam but not to itself. J Pharmacol Exp Ther 2000;295:12411248.

72. McAuley JW, Moore JL, Reeves AL, Flyak J, Monaghan EP, Data J. A pilot study of the neurosteroid ganaxolone in catamenial epilepsy: clinical experience in two patients. Epilepsia 2001;42 Suppl 7:85 (abstract).

73. Herzog AG. Progesterone therapy in women with complex partial and secondary generalized seizures. Neurology 1995;45:1660-1662.

74. Herzog AG. Progesterone therapy in women with epilepsy: a 3-year follow-up. Neurology 1999;52:1917-1918. 